\title{
De novo malignancy after paediatric renal replacement therapy
}

\author{
H M Coutinho, J W Groothoff, M Offringa, M P Gruppen, H S A Heymans
}

\begin{abstract}
Aims-To determine frequency, type, determinants, and outcome of malignancies in children with end stage renal failure. Methods-All Dutch patients, aged less than 15 years, who started chronic renal replacement therapy between 1972 and 1992 and who were at least 18 years old on 1 January 1997, were retrospectively studied.

Results-Mean follow up from first renal replacement therapy was 15.5 years. Twenty two malignancies were found in $\mathbf{2 1}$ of 249 patients. Skin cancer accounted for $59 \%$ and non-Hodgkin lymphoma for $23 \%$ of malignancies. At 25 years after first renal replacement therapy, the probability of developing a malignancy was $17 \%(95 \%$ CI: 9 to 24\%). Compared to the general population the incidence rate for overall cancer was tenfold higher. For nonmelanoma skin cancer and non-Hodgkin lymphoma, standardised risks were 222 and 46 respectively. The use of more than $20 \mathrm{mg} / \mathrm{kg}$ cyclophosphamide showed an association with increased risk of malignancy. Six patients died as a result of their malignancy, accounting for $9.5 \%$ of overall mortality. Whereas four out of five patients with non-Hodgkin lymphoma died, the most frequent malignancy, skin cancer, did not contribute to mortality.

Conclusion-The long term risk of certain malignancies is significantly increased in children who have undergone renal replacement therapy. As an important contributor to overall mortality, awareness of this risk of malignancy in these patients is necessary, especially after treatment with cyclophosphamide.

(Arch Dis Child 2001;85:478-483)
\end{abstract}

Department of

Paediatric Nephrology,

Department of

Paediatrics, Emma

Children's Hospital

AMC, University of

Amsterdam, PO Box

$22700,1100 \mathrm{DE}$

Amsterdam,

Netherlands

H M Coutinho

J W Groothoff

$M$ Offringa

M P Gruppen

H S A Heymans

Correspondence to:

Dr Groothoff

j.w.groothoff@amc.uva.nl

Accepted 13 August 2001
Keywords: renal replacement therapy; malignancy; follow up

The incidence of de novo malignancies in adult recipients of renal transplants is between six and seven times higher than in the general population. ${ }^{12}$ This is thought to be related to the use of immunosuppressive drugs for prevention of graft rejection. Mechanisms through which malignancies can arise include impaired immune surveillance, increased susceptibility to oncogenic viruses, and direct mutagenic effects of the drugs themselves. ${ }^{1-3}$ An increased risk of malignancy has also been described in adult dialysis patients: Inamoto et al found this group to have a 1.4-fold increased risk. ${ }^{4}$
In adult kidney recipients, post-transplant malignancy is known to be an important cause of morbidity and mortality, with cumulative incidences in long term follow up studies varying from $2.6 \%$ to $19.4 \% .^{1{ }^{25-9}}$ Non-melanoma skin cancer is the most frequent malignancy in this group. ${ }^{125681011}$

In young adults with renal insufficiency since childhood, malignancy seems to be much less of a problem, with cumulative incidences varying from $0.8 \%$ to $3.9 \%^{12-15}$; lymphoma is the most frequent malignancy. ${ }^{14-16}$ However, current studies are either based on incomplete data registry or follow up time is relatively short. The long term risk of malignancy in young adults with renal insufficiency since childhood has not been evaluated sufficiently.

We present data from a Dutch national cohort study on Late Effects of Renal Insufficiency in Children (LERIC). The aim of this study, in which completeness of the cohort has been thoroughly assessed, is to determine frequency, type, determinants, and outcome of malignancies in this group of children.

\section{Methods}

STUDY POPULATION

The medical history of all Dutch patients, under 15 years of age, who started chronic renal replacement therapy (RRT) between 1972 and 1992 and who were at least 18 years old on 1 January 1997 was reviewed. Patients who needed RRT for more than four consecutive months were considered to be patients on chronic RRT. The cohort formation was based on data provided by the National Dutch Registry of patients on RRT (RENINE, Rotterdam, Netherlands). RENINE was founded in 1985. The completeness of data approaches $100 \%$ as central registration is obligatory for reimbursement of RRT. RENINE is the Dutch source of the European Dialysis and Transplantation Association (EDTA). Retrospective registration of patients with RRT starting before 1985 was checked by comparing RENINE data with the database of all Dutch centres for paediatric dialysis and kidney transplantation as well as the database of all centres for adult dialysis and transplantation. A list of all patients who fitted our age criteria was submitted to us by RENINE; it contained registry numbers, treatment modality, and the name of the last physician and hospital of treatment. All nephrologists in the Netherlands received a list of those cohort patients, who were under their treatment or had been so during the time of death. We contacted all physicians, asking them whether the list sent by RENINE was consistent with their registry base. Data were collected 
Table 1 Patient characteristics of the LERIC cohort

\begin{tabular}{ll}
\hline & LERIC cohort \\
\hline Number of patients (male/female) & $249(136 / 113)$ \\
Total follow up time from start of RRT & 3870 patient years \\
Mean follow up time from start of RRT, y (range) & $15.5(0.2-30.0)$ \\
Mean age at start of RRT, y (range) & $10.6(1.9-14.9)$ \\
Mean age at first transplantation, y (range) & $11.5(0.0-27.0)$ \\
Number of deaths & 63 \\
Number of patients never transplanted & 18 \\
Mean follow up time of patients never transplanted, y (range) & $1.8(0.3-9.8)$ \\
\hline
\end{tabular}

between November 1998 and July 2000. The study was approved by the Medical Ethical Committee of all participating centres.

DATA COLLECTION

To determine in which centres each patient had been treated, data collection was started in the centres of last treatment according to RENINE. From data found here, a list of all centres of treatment was made for each patient. For these centres, visits were arranged. If patients had been under treatment at two centres simultaneously, both centres were visited, unless all required data were found in one centre. If patients were found to have been treated in additional centres, these were added to the list and were visited as well.

A total of 37 hospitals in the Netherlands were visited by members of the LERIC team to collect and standardise medical histories of all patients included in the study. To achieve this, all available medical charts were reviewed. If charts had been lost or destroyed, data for a particular period could not be collected. These data were listed as missing, although important events such as death and occurrence of malignancy could be obtained from more recent medical information. Recorded data included date of birth, sex, kidney disease, date of first RRT, RRT history, use and type of immunosuppressive agents, total duration or cumulative dose of immunosuppressive agents irrespective of start of RRT, development of malignancy, date of diagnosis, type and outcome of malignancy, and occurrence and cause of death. Data were recorded from the first moment that renal disease led to hospitalisation until either patient death or last registered hospital visit up to July 2000. If uncertainties about malignancies remained, additional information was gathered by contacting the patient's doctor. Malignancies prior to RRT and benign tumours were not included.

DATA ANALYSIS

Standardised risks were determined by calculating the expected number of malignancies based on the 1996 report of Incidence of Cancer in the Netherlands of the Netherlands Cancer Registry. ${ }^{17}$ These national data provide cancer incidence in the general population with a completeness of more than $95 \%$. Nine regional cancer registries receive lists of newly diagnosed cases on a regular basis from the pathology and haematology departments in their region. In addition, lists of hospitalised cancer patients are obtained, based on data from the National Registry of Hospital Discharge Diagnosis (Landelijke Medische Registratie). After extensive checks for inconsistencies and duplicate records, the data are entered into the national database. All malignant and in situ malignancies are registered, except for basal cell carcinomas of the skin and carcinoma in situ of the cervix. As these malignancies are often removed without affirmation of the diagnosis by pathologist laboratories, registration of their incidence would not be reliable. Skin cancer is recorded per type per patient, unless new lesions arise more than three months after diagnosis. A malignancy first discovered at autopsy is also included in the cancer registry. For all comparisons with the LERIC cohort we used an age and gender matched group of the general population. Calculation of standardised risks was based on the incidence rates in the Netherlands between 1992 and 1996, whereas our study cohort consists of all Dutch patients, aged under 15 years, who started chronic RRT between 1972 and 1992 and were at least 18 years old on 1 January 1997. No national registry for cancer incidence existed in the Netherlands until 1989. We therefore assumed that the incidence of cancer in the Netherlands was that between 1992 and 1996, that incidence remained constant between 1972 and 1992, and that incidence was distributed in a homogeneous way in the $0-44$ year old age group. The standardised risk in the skin cancer group was calculated with the exclusion of basal cell carcinomas.

SPSS 9.0 and CIA (Confidence Interval Analysis, Prof. M J Gardner and British Medical fournal) were used for statistical calculation. For all factors marked with an asterisk in table 4 , persons with the value zero were included in the reference group. Kaplan-Meier analysis was performed to determine cumulative cancer incidence. Cox regression analysis was performed to analyse potential risk factors. Time was defined as the amount of patient years at risk, with risk starting at first RRT (this is the moment one is considered a patient) and ending at diagnosis of malignancy, last recorded hospital visit, or patient death. If potentially oncogenic drugs such as cyclophosphamide were given before start of RRT, these were included.

\section{Results}

PATIENT CHARACTERISTICS

Table 1 shows patient characteristics of the whole of the LERIC cohort. From first RRT a total of 3870 patient years was recorded, with data of 81 patient years missing. Mean follow up was 15.5 years per patient. For 82 patients (33\%) follow up was more than 20 years. At the end of the study no patients were lost to follow up. Eighteen patients never underwent transplantation; mean follow up time from first RRT was 1.8 years and 17 patients died within a mean time of 1.4 years after start of RRT (range 0.3-4.0). Sixty seven patients were transplanted once, 118 twice, 38 three times, and eight four times. Treatment modality at the 
Table 2 Characteristics of malignancies in the LERIC cohort

\begin{tabular}{|c|c|c|c|c|c|}
\hline Type & $\begin{array}{l}\text { No. of } \\
\text { tumours }\end{array}$ & $\begin{array}{l}\text { Mean age at } \\
\text { diagnosis of } \\
\text { malignancy, } y \\
\text { (range) }\end{array}$ & $\begin{array}{l}\text { Interval between first } \\
\text { transplantation and } \\
\text { diagnosis, } y \text { (range) * }\end{array}$ & $\begin{array}{l}\text { Mean follow up time } \\
\text { after diagnosis, } y \\
\text { (range) }\end{array}$ & $\begin{array}{l}\text { No. of patients } \\
\text { who died due to } \\
\text { malignancy }\end{array}$ \\
\hline Skin cancer & 13 & $27.8(14.3-34.5)$ & $15.0(5.5-20.2)$ & $3.6(0.4-12.9)$ & 0 \\
\hline SCC & 7 & & & & 0 \\
\hline BCC & 3 & & & & 0 \\
\hline Melanoma & 2 & & & & 0 \\
\hline M. Bowen & 1 & & & & 0 \\
\hline Non-Hodgkin lymphoma & 5 & $23.5(11.1-31.1)$ & $11.7(0.6-19.9)$ & $0.6(0.0-1.7)$ & 4 \\
\hline ALL & 1 & & & & 1 \\
\hline Fibrosarcoma & 1 & & & & 1 \\
\hline Grawitz tumour & 1 & & & & 0 \\
\hline Leiomyosarcoma & 1 & & & & 0 \\
\hline Total & 22 & $25.9(11.1-34.5)$ & $12.9(0.1-21.1)$ & $2.6(0.0-12.9)$ & 6 \\
\hline
\end{tabular}

$\star$ Excluding one patient with malignant melanoma who never underwent transplantation.

SCC, squamous cell carcinoma; BCC, basal cell carcinoma; ALL, acute lymphatic leukaemia.

start of RRT was haemodialysis in $81 \%$, peritoneal dialysis in $16 \%$, and transplantation in $3 \%$.

INCIDENCE AND TYPE OF MALIGNANCY

Twenty two malignancies were found in 21 of the 249 patients $(8.4 \%$ of those included in the study). Table 2 shows type, frequency, and age at diagnosis of malignancy, as well as interval between first transplantation and diagnosis of malignancy, follow up time recorded after diagnosis of malignancy, and death as a result of malignancy. Except for one patient with malignant melanoma, all patients with malignancies had been transplanted at least once. Thirteen patients had skin cancer $(57 \%$ of all malignancies) and five had non-Hodgkin lymphoma (24\%). The other malignancies found were one case of acute lymphatic leukaemia, one abdominal fibrosarcoma, one Grawitz tumour of the own kidney, and one leiomyosarcoma of the bladder. In the skin cancer group the ratio of basal cell carcinoma versus squamous cell carcinoma was 3:7. Some of the patients with skin cancer had lesions at multiple locations.

Mean age at diagnosis of malignancy was 25.9 years (SD 6.6, range 11.1-34.5), but skin cancer developed at a later mean age than nonHodgkin lymphoma (at 27.8 and 23.5 years, respectively). The mean interval between first RRT and diagnosis of cancer was 13.8 years (SD 6.5, range 1.3-23.1). With 12 male and nine female patients, sex distribution in the malignancy group was comparable to the whole LERIC cohort as well as to the whole of the Netherlands in 1996 (51\% male, $49 \%$ female).

STANDARDISED RISKS

Figure 1 shows the probability of developing a malignancy as a function of time since start of RRT (Kaplan-Meier analysis). At 25 years after first RRT the risk of developing a malignancy was $17 \%$ (95\% CI: 9 to $24 \%$ ). The increase in risk was most notable at 15 years after first RRT. Table 3 shows standardised risks of developing a malignancy. Compared to the general population the overall risk was tenfold higher for patients in the LERIC cohort, with a larger risk for males than for females for overall cancer, non-melanoma skin cancer, and non-Hodgkin lymphomas. For non-melanoma skin cancer and non-Hodgkin lymphoma, standardised risks were 222 and 46 respectively. In the skin cancer group basal cell carcinoma was excluded, because no national registration exists for this tumour. This type of skin cancer is often removed without affirmation of diagnosis by pathologist laboratories. Therefore registration of its incidence would not be reliable.

\section{DETERMINANTS}

Table 4 shows variables analysed as potential risk factors. Only the use of more than 20 $\mathrm{mg} / \mathrm{kg}$ cyclophosphamide was associated with an increased risk of malignancy. Standardised risk increased with increasing dosage. Even when the one patient with cancer of the bladder

Table 3 Standardised risk of developing a malignancy for the LERIC cohort

\begin{tabular}{|c|c|c|c|c|c|c|c|c|c|c|c|}
\hline & $\begin{array}{l}\text { No. of } \\
\text { patients }\end{array}$ & $\begin{array}{l}\text { Years at } \\
\text { risk }\end{array}$ & $\begin{array}{l}\text { Overall } \\
\text { cancer rate } \\
\text { LERIC } \\
\text { (per } 1000 \\
\text { person } \\
\text { years) }\end{array}$ & $\begin{array}{l}\text { Overall cancer } \\
\text { rate } \\
\text { population } \\
\text { (per } 1000 \\
\text { person years) }\end{array}$ & $\begin{array}{l}\text { SR overall } \\
\text { cancer }(95 \% \\
\text { CI) }\end{array}$ & $\begin{array}{l}\text { NMSC rate } \\
\text { LERIC (per } \\
1000 \text { person } \\
\text { years)t }\end{array}$ & $\begin{array}{l}\text { NMSC rate } \\
\text { population } \\
\text { (per } 1000 \\
\text { person } \\
\text { years) } t\end{array}$ & $\begin{array}{l}S R N M S C \\
(95 \% C I) t\end{array}$ & $\begin{array}{l}\text { NHL rate } \\
\text { LERIC (per } \\
1000 \text { person } \\
\text { years) }\end{array}$ & $\begin{array}{l}\text { NHL rate } \\
\text { population (per } \\
1000 \text { person } \\
\text { years) }\end{array}$ & $\begin{array}{l}\text { SR NHL } \\
(95 \% C I)\end{array}$ \\
\hline Overall & 249 & 3870 & 5.7 & 0.56 & $10(6.3-15.1)$ & 2.1 & 0.0093 & $\begin{array}{l}222 \\
(96-438)\end{array}$ & 1.3 & 0.028 & $\begin{array}{l}46 \\
(15-108)\end{array}$ \\
\hline Male & 136 & 2171 & 5.5 & 0.43 & $13(6.9-23.3)$ & 2.3 & 0.01 & $\begin{array}{l}230 \\
(74-530)\end{array}$ & 1.8 & 0.038 & $\begin{array}{l}47 \\
(13-124)\end{array}$ \\
\hline Female & 113 & 1699 & 5.3 & 0.68 & $8(3.6-14.9)$ & 1.8 & 0.0087 & $\begin{array}{l}203 \\
(42-593)\end{array}$ & 0.59 & 0.018 & $\begin{array}{l}33 \\
(1-182)\end{array}$ \\
\hline
\end{tabular}

Calculations of standardised risks are based on incidence rates per 100000 person years for invasive tumours among males and females in the range $0-44$ years according to the 1996 report of Incidence of Cancer in the Netherlands of the Netherlands Cancer Registry. ${ }^{17}$ The LERIC cohort was compared to an age matched group of the general population in the Netherlands between 1992 and 1996.

Confidence intervals were calculated with CIA (Confidence Interval Analysis, Prof. MJ Gardner and British Medical fournal).

*Years at risk defined as time between first renal replacement therapy and diagnosis of malignancy, last recorded hospital visit, or patient death.

†Basal cell carcinoma is excluded, because no national registration exists for this tumour.

SR, standardised risk; NMSC, non-melanoma skin cancer; NHL, non-Hodgkin lymphoma. 


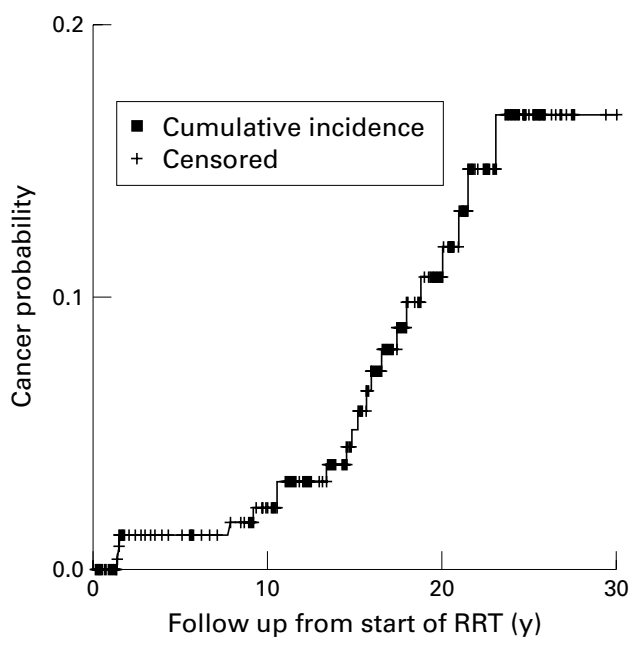

Figure 1 Probability of cancer as a function of time since start of RRT.

was excluded, the use of $100-200 \mathrm{mg} / \mathrm{kg}$ cyclophosphamide still showed an increased risk of malignancy (RR 3.62 and 3.47, respectively; $95 \%$ CI: 1.4 to 9.6 and 1.2 to 10.2 , respectively). A total of 37 patients (15\%) were treated with cyclophosphamide at some point. Within this group, mean cumulative dose of cyclophosphamide was $950 \mathrm{mg} / \mathrm{kg}$ for those who developed cancer and $244 \mathrm{mg} / \mathrm{kg}$ for those who did not.

Patient gender, age at first RRT, and age at first transplantation did not contribute to the risk of malignancy. Neither did total transplantation time or use, total duration of use, and cumulative dose of other immunosuppressive agents. Haemodialysis or peritoneal dialysis did not contribute to this risk. Our sample size was too small to evaluate transplantation as a risk factor.

OUTCOME

Nine of the 21 patients died; six of these deaths were directly related to malignancy. Four of these were a result of non-Hodgkin lymphoma, one acute lymphatic leukaemia, and one fibrosarcoma. The other three patients died from infection, sclerosing peritonitis, and cardiac arrest of unknown cause. Overall 63 patients died in the LERIC cohort. Therefore, 9.5\% of all deaths in the LERIC cohort were a result of malignancy. The mean time of malignancy related death was 9.4 months after diagnosis. In the non-Hodgkin subgroup this was 3.5 months. The mortality/incidence ratio for all malignancies in the LERIC cohort was 0.29 , compared to 0.23 in this age group in the general population. For non-Hodgkin lymphomas these ratios were 0.80 and 0.27 , respectively.

In 11 patients with skin cancer the lesion was excised or treated successfully. Two patients with squamous cell carcinoma and melanoma died of causes unrelated to cancer, one year and more than two years after diagnosis of skin cancer, respectively.

\section{Discussion}

SUMMARY OF RESULTS

This long term follow up study of late effects of renal insufficiency in children shows a probability of developing malignancies of $17 \%$ at 25 years after first RRT, the majority being skin cancers and non-Hodgkin lymphomas. Compared to the general population the risk of developing a malignancy for our patients was tenfold higher. For non-melanoma skin cancer the standardised risk was 222; for nonHodgkin lymphoma it was 46. Cumulative cyclophosphamide dose $>20 \mathrm{mg} / \mathrm{kg}$ was associated with an increased risk of malignancy. Finally, malignancies contributed to a significant proportion of overall mortality (9.5\%), although the most frequent malignancy, skin cancer, resulted in no deaths.

INCIDENCE AND TYPE OF MALIGNANCY

In a study in paediatric renal transplant recipients comparable to the LERIC study, Offner and colleagues ${ }^{12}$ found an incidence of malignancy of $2.7 \%$ after a mean of 13.1 years follow up. With a slightly higher mean follow up of 16.6 years we found a fourfold higher incidence. This difference could be explained by a more complete search strategy in the LERIC study; Offner et al contacted patients by telephone to enquire about medical events instead of reviewing medical charts, as was done in the LERIC study. This might have led

Table 4 Variables analysed as potential risk factors for development of malignancy in the LERIC cohort

\begin{tabular}{|c|c|c|c|c|}
\hline Variable (index versus reference) & $\begin{array}{l}\text { Index group: cancer/ total } \\
\text { exposed }\end{array}$ & $\begin{array}{l}\text { Reference group: cancer/ } \\
\text { total not exposed }\end{array}$ & Relative risk & $95 \%$ confidence interval \\
\hline Male sex & $12 / 136$ & $9 / 113$ & $1.04 \dagger$ & $0.44-2.47$ \\
\hline Total transplantation time more than 1 year ${ }^{\star}$ & $18 / 204$ & $3 / 45$ & $1.32 \ddagger$ & $0.41-4.30$ \\
\hline Total transplantation time more than 6 years ${ }^{\star}$ & $16 / 183$ & $5 / 66$ & $1.15 \ddagger$ & $0.44-3.03$ \\
\hline Use of azathioprine & $20 / 226$ & $1 / 23$ & $2.04 \ddagger$ & $0.29-14.50$ \\
\hline Use of azathioprine in skin cancer group & $12 / 226$ & $1 / 23$ & $1.22 \ddagger$ & $0.17-8.97$ \\
\hline Use of cyclosporine & $13 / 147$ & $8 / 102$ & $1.13 \ddagger$ & $0.49-2.62$ \\
\hline Use of azathioprine and cyclosporine & $13 / 138$ & $8 / 111$ & $1.31 \neq$ & $0.56-3.04$ \\
\hline Use of methylprednisolone & $12 / 157$ & 9/92 & $0.78 \ddagger$ & $0.34-1.78$ \\
\hline Use of ATG & $6 / 77$ & $15 / 172$ & $0.89 \ddagger$ & $0.36-2.21$ \\
\hline Use of OKT3 & $2 / 28$ & $19 / 221$ & $0.83 \ddagger$ & $0.20-3.38$ \\
\hline Use of cyclophosphamide & $6 / 37$ & $15 / 212$ & $2.29 \ddagger$ & $0.95-5.53$ \\
\hline $\begin{array}{l}\text { Dose of cyclophosphamide (more than } 20 \mathrm{mg} / \mathrm{kg} \text { compared } \\
\text { to less than } 20 \mathrm{mg} / \mathrm{kg} \text { or none) }{ }^{\star}\end{array}$ & $6 / 34$ & $15 / 215$ & $2.53 \ddagger$ & $1.05-6.07$ \\
\hline $\begin{array}{l}\text { Dose of cyclophosphamide (more than } 100 \mathrm{mg} / \mathrm{kg} \\
\text { compared to less than } 100 \mathrm{mg} / \mathrm{kg} \text { or none })^{\star}\end{array}$ & $5 / 17$ & $16 / 232$ & $4.26 \neq$ & $1.78-10.20$ \\
\hline
\end{tabular}

${ }^{\star}$ Patients with the value 0 were included in the reference group.

†Relative risks and $95 \%$ confidence intervals were calculated with the Cox regression method. Time was defined as the amount of patient years at risk with risk starting at first renal replacement therapy (this is the moment one is considered a patient) and ending at diagnosis of malignancy, last recorded hospital visit, or patient death; a total of 3870 patient years was recorded according to this definition.

$\ddagger$ Relative risks were calculated with CIA (Confidence Interval Analysis, Prof. MJ Gardner and British Medical fournal). 
to an underreporting of skin cancer by Offner et al. Furthermore, we found that risk of malignancy strikingly increased at 15 years after start of RRT. The difference in mean follow up, although small, could therefore also have contributed to the lower incidence found by Offner et al.

Similar types of malignancy were found in the LERIC study as in adult studies of renal transplant recipients. ${ }^{10}{ }^{18-20}$

The ratio of basal cell carcinoma versus squamous cell carcinoma was 3:7 and thus reversed compared to the general population. In adult studies of renal transplant recipients similar findings have been reported, ${ }^{2} 10^{21}$ but none of these studies have reported an explanation. It has been postulated that squamous cell carcinomas are more susceptible to decreased cellular immunity caused by immunosuppressive agents than basal cell carcinomas. Furthermore, infection with human papillomavirus (HPV), frequently seen in immunosuppressed patients, might increase chances of developing squamous cell carcinomas rather than basal cell carcinomas (personal communication). However, this still has to be investigated.

Non-Hodgkin lymphoma occurred at a younger mean age than skin cancer and had the potential to develop sooner after first transplantation (after a minimum of 0.62 years compared to 5.48 years in skin cancer). Both Opelz and Henderson ${ }^{22}$ and Penn ${ }^{19}$ described this phenomenon in adult studies of renal transplant recipients. Penn ${ }^{19}$ suggested that non-Hodgkin lymphomas develop during the first few months after transplantation because of a high degree of immunosuppression following the use of multiple immunosuppressive agents. Epstein-Barr virus (EBV) plays an important role in development of nonHodgkin lymphomas. ${ }^{11} 131419$ EBV infection of B lymphocytes can lead to uncontrolled cell growth and proliferation. ${ }^{11}$ Unfortunately we have no data on exposure of our patients to this oncogenic virus. Gaya et al found that the risk of developing skin cancer increased with time after transplantation. ${ }^{1}$ Impairment of normal DNA repair mechanisms as a result of immunosuppressive drugs, combined with cumulative UV light induced damage may be responsible for the apparent latency period of several years before skin cancer develops. Skin cancer education of patients with RRT, for example, avoidance of excessive sunlight exposure, might lead to a longer latency period or even prevent the development of skin cancer.

\section{STANDARDISED RISKS}

We found a standardised risk (SR) of 10 for all malignancies compared to the general population. For non-melanoma skin cancer and nonHodgkin lymphoma, however, standardised risks were 222 and 46 . Not many studies have compared cancer incidence among RRT recipients to that of the general population. Opelz and Henderson ${ }^{22}$ found an SR of 37 for non-Hodgkin lymphoma in renal transplant recipients in the first post-transplant year. Gaya et al reported an SR of 6 for overall cancer, 19 for skin cancer, and 45 for non-Hodgkin lymphoma in renal transplant recipients after an average follow up of 9.6 years. ${ }^{1}$ The tenfold higher SR that we found for skin cancer compared to Gaya et al may be related to our longer follow up time.

Standardised risks were based on the incidence rates of malignancies in the Netherlands between 1992 and 1996, whereas malignancies in the LERIC cohort had developed before 1992. Considering the fact that overall and skin cancer incidences in the Netherlands in persons aged 0-44 years have increased since $1989,{ }^{17}$ the standardised risk of the LERIC cohort could be underestimated.

\section{DETERMINANTS}

The crude association of cumulative cyclophosphamide dose of $>20 \mathrm{mg} / \mathrm{kg}$ with increased risk of development of malignancies suggests a potential carcinogenic effect. This analysis was based on small numbers, yet careful use of this immunosuppressive agent is warranted. Development of malignancies secondary to the use of cyclophosphamide has been described: cancer of the bladder as well as acute myeloid leukaemia. ${ }^{23}{ }^{24}$ The immunosuppressive agent cyclophosphamide can lead to an increased risk of uncontrolled cell growth and proliferation, and invasion or reactivation of oncogenic viruses such as EBV. ${ }^{23}$ Furthermore, acrolein, the major toxic metabolite of cyclophosphamide, has been reported to induce bladder cancer in rats. ${ }^{25}$ Travis et al reported that cyclophosphamide related bladder cancer was dose dependent. ${ }^{24}$ We found evidence of an association between the risk of overall malignancies and dose of cyclophosphamide. Although we found only one case of bladder cancer, analysis of cyclophosphamide as a risk factor with exclusion of this case of bladder cancer still showed an increased risk of malignancy for cumulative doses of 100-200 $\mathrm{mg} / \mathrm{kg}$.

\section{OUTCOME}

Six of 21 patients died as a result of their malignancy, none of which were a result of skin cancer. Although this is the most frequent malignancy associated with renal transplantation, it therefore seems to be mainly contributing to morbidity, but not mortality. However, as the mean follow up time after diagnosis of skin cancer was only 3.6 years, no definitive conclusions can be drawn. On the other hand, as in the general population mortality caused by non-melanoma skin cancer is extremely low, ${ }^{17}$ the same might be expected for the LERIC cohort as well. Non-Hodgkin lymphomas did contribute in a significant number to both morbidity and mortality: four of five patients died in our cohort. They also caused death more rapidly than other malignancies in our cohort. Cessation or dose reduction of immunosuppressive agents has been reported to lead to tumour regression in non-Hodgkin lymphomas. ${ }^{36}$ This is something clinicians need to be aware of in order to try to reduce mortality caused by this type of cancer. 
One Grawitz tumour was diagnosed by coincidence in a patient who is currently alive. As this type of cancer leads to death in nearly every case, mortality in the LERIC cohort could easily have been higher.

Malignancies in immunocompromised individuals and possibly also in chronic dialysis patients appear to be more aggressive and more difficult to treat, hence both morbidity and mortality are prone to be higher compared to malignancies in the general population..$^{3-518}$ The mortality/incidence ratio we found for overall cancer and non-Hodgkin lymphomas supports these findings.

LIMITATIONS OF THE STUDY

Inherent to studies of relatively rare paediatric diseases, our sample size was fairly small. Furthermore, the study design was retrospective and data were collected from multiple centres. We nevertheless believe this long term study provides as complete a picture as possible on frequency, type, determinants, and outcome of malignancies after paediatric RRT. No patients were lost to follow up, and data on important events such as occurrence of malignancy were not missing.

\section{CONCLUSION}

In conclusion, the long term risk of certain malignancies is significantly increased in children with RRT. Although the most frequent malignancy, skin cancer, resulted in no deaths, the fact that malignancy related death represented $9.5 \%$ of overall mortality warrants further research on this subject.

In patients treated with more than $20 \mathrm{mg} / \mathrm{kg}$ of cyclophosphamide extra vigilance towards the development of malignancies is required. Regular medical check ups, such as routine control by dermatologists and skin cancer education of patients, could decrease both morbidity and mortality caused by malignancy as a late effect of paediatric RRT.

Bella Drost, Janneke van den Broek, Anouk van der Graaf and Jeroen Hutten, all medical students, contributed to the data colection. Birgit van Benthem, GG\&GD Amsterdam, provided statistical advise. Dr Huib Caron gave advise on oncological aspects. Staff members of the Netherlands Cancer Registry were very helpful with the interpretation of data of the 1996 report of Incidence of Cancer in the Netherlands. Data collection was made possible by the cooperation of the following physicians: RJ Hene, Medical Centre University Utrecht; JJ Homan van der Heide, Academic Hospital Groningen; MR Lilien, Wilhemina Children's Hospital, Utrecht; NJ van der Kar, St Radboud Hospital, Nijmegen; M Kooistra, Dianet, Utrecht; JW van der Pijl Medical Centre University Leyden; EJ Rischen-Vos, Dijkzig Hospital, Rotterdam; S Surachno, Academic Medical Centre, Amsterdam; ED Wolff, Sophia Children's Hospital, Rotterdam AJ Apperloo, St Elisabeth Hospital, Tilburg; M Boekhout, Rijnland Hospital, Leiderdorp; J Boonakker, Reinier de Graaf Gasthuis, Delft; MHL Christiaans, Academic Hospital, Maas-
tricht; PPNM Diderich, St Fransiscus Gasthuis, Rotterdam; tricht; PPNM Diderich, St Fransiscus Gasthuis, Rotterdam;
MA van Dorpel, St Clara Hospital, Rotterdam; WT van Dorp,
Kennemer Gasthuis, Haarlem; WJ Fagel, Medical Centre LeeuKennemer Gasthuis, Haarlem; WJ Fagel, Medical Centre Leeu-
warden; PG Gerlag, St Joseph Hospital, Veldhoven; A van Es, warden; PG Gerlag, St Joseph Hospital, Veldhoven; A van Es, Dialysis Centre 't Gooi, Hilversum; AB Geers, St Antonius Hospital, Nieuwegein; EG Hagen, Hospital De Lichtenberg, Amersfoort; SJ Hoorntje, Catharina Hospital, Eindhoven; RM Huisman, Dialysis Centre Groningen; K Jie, Groene Hart Hospital, Gouda; GMTh de Jong, Drechsteden Hospital, Dordrecht; AJ Hoitsma, St Radboud Hospital Nijmegen; G Kolster,
Isala Clinics, Zwolle; I Keur, Dianet Buitenveldert, Amsterdam; WAH Koning-Mulder, Medical Spectre Twente, Enschede; AG Lieverse, Diaconessenhuis, Eindhoven; PB Leurs, Oosterschelde Hospital, Goes; N vd Lely, Reinier de Graaf Gasthuis, Delft; MJ Nubé, Medical Centre Alkmaar; C Oldenbroek, Westfries Gasthuis, Hoorn; MJM Smit, Juliana Children's Hospital, The Hague; G Vastenburg, Scheper Hospital, Emmen; RM Valentijn, Red Cross Hospital, The Hague; AE v Wijk, Hospital Free University, Amsterdam. Financial Support for the study was provided by the Dutch Kidney Foundation (Nierstichting Nederland)

1 Gaya SBM, Rees AJ, Lechler RI, et al. Malignant disease in patients with long-term renal transplants. Transplantation 1995;59:1705-9.

2 London NJ, Farmery SM, Will EJ, et al. Risk of neoplasia in renal transplant recipients. Lancet 1995;346:403-6.

3 Liebelt AG. Malignant neoplasms in organ transplant recipients. In: Kaiser HE, ed. Cancer growth and progression. Vol. 6, Etiology of cancer in man. Dordrecht: Kluwer Academic Publishers, 1988:136-65.

4 Inamoto $\mathrm{H}$, Ozaki R, Matsuzaki $\mathrm{T}$, et al. Incidence and mortality pattern of malignancy and factors affecting the risk of malignancy in dialysis patients. Nephron 1991;59:611-17.

5 Krueger TC, Tallent MB, Richie RE, et al. Neoplasia in immunosuppressed renal transplant patients: a 20-year experience. Southern Med f 1985;78:501-6.

6 Längle F, Mühlbacher F, Steininger R, et al. Long-term outcome in renal patients beyond five years after kidney transplantation. Transplant Proc 1989;21:2176-8.

7 Behrend M, Kolditz M, Kliem V, et al. Malignancies in patients under long-term immunosuppression after kidney transplantation. Transplant Proc 1997;29:834-5.

8 Yasamura T, Oka T, Nakane Y, et al. Long-term prognosis of renal transplant surviving for over $10 \mathrm{yr}$, and clinical, renal and rehabilitation features of 20-yr successes. Clin Transplant 1997;11:387-94.

9 Hoshida Y, Tsukuma H, Yasunaga Y, et al. Cancer risk after renal transplantation in Japan. Int f Cancer 1997;71:51720

10 Bouwes Bavinck JN, Vermeer BJ, Claas FHJ, et al. Skin cancer and renal transplantation. $\mathcal{F}$ Nephrol 1994;7:261-7.

11 Melosky B, Karim A, Chui A, et al. Lymphoproliferative disorders after renal transplantation in patients with triple or quadruple immunosuppression. F Am Soc Nephrol 1992; ::S290-4

12 Offner G, Latta K, Hoyer PF, et al. Kidney transplanted children come of age. Kidney Int 1999;55:1509-17.

13 Gagnadoux MF. Risk of malignancy in pediatric renal transplant recipients [in French]. Ann Pédiatr (Paris) 1997;44: 187-92.

14 Nocera A, Ghio L, Dall'Amico R, et al. De novo cancers in paediatric renal transplant recipients: a multicentre analysis within the North Italy Transplant programme (NITp), Italy. Eur $\mathcal{F}$ Cancer 2000;36:80-6.

15 Wingen AM, Wiesel M, Möhring K, et al. Malignancies in children with renal replacement therapy. Transplant Proc 1994;26:5-6.

16 Penn I. Posttransplant malignancies in pediatric organ transplant recipients. Transplant Proc 1994;26:2763-5.

17 Netherlands Cancer Registry. Incidence of cancer in the Netherlands 1996: eighth report of the Netherlands Cancer Registry. Netherlands Cancer Registry (NCR), for data on mortality and demography. Statistics Netherlands/Centraal Bureau voor de Statistiek, March 2000

18 Barrett WL, Roy First M, Aron BS, Penn I. Clinical course of malignancies in renal transplant recipients. Cancer 1993; 72:2186-9.

19 Penn I. Cancers complicating organ transplantation. N Engl 7 Med 1990;323:1767-9.

20 Brunner FP, Landais P, Selwood NH, on behalf of the EDTA-ERA Registry Committee. Malignancies after renal transplantation: the EDTA-ERA registry experience. Nephrol Dialyis Transplant 1995;10(suppl 1):74-80.

21 Penn I. The changing pattern of posttransplant malignancies. Transplant Proc 1991;23:1101-3.

22 Opelz G, Henderson R. Incidence of non-Hodgkin lymphoma in kidney and heart transplant recipients. Lancet 1993;342:1514-16.

23 Roberts MM. Acute leukaemia after immunosuppressive therapy. Lancet 1976;2:768-70.

24 Travis LB, Curtis RE, Glimelius B, et al. Bladder and kidney cancer following cyclophosphamide therapy for noncancer following cyclophosphamide therapy for non-
Hodgkin's lymphoma. $\mathcal{7}$ Natl Cancer Inst 1995;87:524-30.

25 Cohen SM, Garland EM, St John M, et al. Acrolein initiates rat urinary bladder carcinogenesis. Cancer Res 1988;52: 3577-81.

26 Starzl TE, Nalesnik MA, Porter KA, et al. Reversibility of lymphomas and lymphoproliferative lesions developing under cyclosporine-steroid therapy. Lancet 1984;1:583-7. 